\title{
A Novel Speed Control Strategy for Five Phases Permanent Magnet Synchronous Motor with Linear Quadratic Regulator
}

\author{
N. Venkata Ramana ${ }^{1}$, V. L. N. Sastry ${ }^{2 *}$ \\ ${ }^{1}$ Dept. of EEE, Shri Vishnu Engineering College for Women (Autonomous), Bhimavaram, West Godavari \\ District, Andhra Pradesh, India. \\ ${ }^{2}$ Dept. of EEE, SASI Institute of Technology and Engineering, Tadepalligudem, West Godavari District, \\ Andhra Pradesh, India. \\ * Corresponding author. Tel.: +91-7382439972; email: sastry@sasi.ac.in \\ Manuscript submitted August 28, 2015; accepted December 8, 2015. \\ doi: 10.17706/ijcee.2015.7.6.408-416
}

\begin{abstract}
The paper proposes the application of linearized mathematical model for five phases permanent magnet synchronous motor with the help of vector control theory. The linear quadratic regulator (LQR) is examined as an optimal speed controller for five phases permanent magnet synchronous motor. The designed linear quadratic regulator (LQR) based control technique is simulated in MATLAB/ Simulink environment and the performance is compared with the conventional PI control strategy. All the simulation studies have led to better and robust dynamic performance in terms of Linear Quadratic Regulator.
\end{abstract}

Key words: Five phases permanent magnet synchronous motor (PMSM), linear quadratic regulator (LQR), PI controller.

\section{Introduction}

The Permanent Magnet Synchronous motors are being used in place of conventional dc motors in recent years. These motors have special features like high efficiency, and high power density. In the proposed study the three phase permanent magnet synchronous motor is replaced with a multiphase motor to gain the advantage of the multiphase drive systems. The multiphase systems have more advantages compared to the three phase systems like high output power rating, less harmonics in the dc link current, low torque pulsations and stable speed response. At present multiphase drive, systems have gained increasing demand owing to their better performance and stable operation even when load fluctuations occur.

The advent of modern Permanent Magnets (PM) with significant amount of energy density led to the evolution of dc machines with PM field excitations in the 1950s. Windings and external energy sources were eliminated with the use of permanent magnets [1]. Therefore, the size of the machine reduced. In the late 1950s, the availability of switching power devices paved the way for the replacement of the mechanical commutator with an electronic commutator. As a result, brushless dc and synchronous machines were developed. In these machines, as the armature of the dc machines are on the stator side, it was possible to gain higher voltages and cooling. In the place of windings in the rotor as the excitation field, PM poles have been used to reduce the electrical loss.

Usually, the variable speed drives [2] use power electronic converters for operation. As the power electronic converters are unable to produce the required voltage levels to drive the variable speed drives, 
the power electronic converters were replaced with multilevel inverters. It is because the semiconductor devices in the power electronic converters have limitations on power rating. They can produce only up to certain voltage levels, which are not adequate to drive the variable speed drives.

To avoid the above problem, multilevel inverters are used to get high power rating. The advent of inverter fed motor drives also removed the limitation of the number of motor phases. Hence, it has become possible to design multi-phase motor drives i.e. the drives with more than three phases.

In multi-phase machines, the required power between multiple phases is divided into small voltage levels than it is in the conventional three phase drives. It enables flexibility in the design of power electronic converters with limited power ranges to drive multi-phase machines. It also offers scope for producing higher voltage levels. The problem of insulating the higher voltages in multi-phase machine drives can be overcome by designing the converter with low voltage levels.

Multi-phase motor drives [2] possess more advantages than the conventional three-phase motor drives such as

1) Reducing the amplitude and increasing the frequency of torque pulsation.

2) Reducing the stator current per phase without increasing the voltage per phase.

3) Increasing the reliability and power density.

4) Increasing the torque producing capability of the motor.

5) Adjusting of the torque and flux linkages of the five-phase direct torque controlled system in a better ways.

The permanent magnet synchronous motors have high torque to inertia ratio and power density. These motors are built with strong magnetic material like Samarium Cobalt and Neodymium Iron Boron and provide better short-time overload capability than Induction motors. The application of five-phase PMSM is a better economic alternative than Induction motors for low speed operation in direct drives.

To overcome major failures such as open circuit of a single or two phases and short circuit of one phase in three phase PMSM drives, five phase PMSM drives are introduced. In high speed application, five-phase PMSM have an extended flux weakening region because of their reluctance torque and ruggedness of rotor. Proper rotor design is one of the best ways to minimize torque pulsation in multiphase PMSM drives. The five-phase PMSM motors are simple to manufacture and easy to installation.

In this paper, a detailed mathematical model for a five phase PMSM is developed using vector control theory to analyze the speed controlling process. The vector control method has both Park's and Clarke's transformations which can transform the five phase currents into the corresponding field current and the torque currents. In general the PI control technique has the advantage of better performance of PMSM in terms of speed control, especially in practical aspects. However, these controllers do not provide satisfactory results in other applications.

To avoid the unsatisfactory behavior of PI control techniques for speed response of PMSM an alternative method like Linear Quadratic Regulator (LQR) is introduced for better dynamic response [3], [4]. In many of the classical control techniques closed loop performance is obtained by using higher values of gains. These higher values of gains result in larger power amplifications but in practice these higher values of gains are difficult to model. To avoid the problem of practical implementation for higher gains in classical control techniques, there is a requirement to implement the optimal control technique with better closed loop performance. LQR is an optimal control methodology with quadratic cost function for the dynamic performance of the system. As the LQR is an optimal control technique, the nonlinear mathematical model needs to be linearized to apply this control strategy.

The main emphasis of this paper is to apply the LQR to get the improved speed response of five phases PMSM. The results obtained are compared with those of the PI control technique. The paper is organized as follows: Section 2 deals with the decoupled mathematical model for a five phases PMSM. Section 3 discusses 
the principle and operation of LQR and the design of optimal control technique for five-phase PMSM using quadratic cost function. Section 4 presents the MATLAB/SIMULINK results of five-phase PMSM using PI and LQR. Section 5 concludes and gives the future directions of this paper.

\section{Mathematical Modeling of Five Phases PMSM}

The dynamic equations of a five phases permanent magnet synchronous motor are expressed in rotor reference frame theory as given below:

$$
\begin{gathered}
\frac{d}{d t} i_{q 1}=\frac{1}{L_{q}} v_{q 1}-\frac{R}{L_{q}} i_{q 1}-\frac{L_{d}}{L_{q}} p \omega_{r} i_{q 1}-\frac{\lambda p \omega_{r}}{L_{q}} \\
\frac{d}{d t} i_{d 1}=\frac{1}{L_{d}} v_{d 1}-\frac{R}{L_{d}} i_{d 1}+\frac{L_{q} p \omega_{r}}{L_{d}} i_{q 1} \\
\frac{d}{d t} i_{q 2}=\frac{1}{L_{q}} v_{q 2}-\frac{R}{L_{q}} i_{q 2} \\
\frac{d}{d t} i_{d 2}=\frac{1}{L_{d}} v_{d 2}-\frac{R}{L_{d}} i_{d 2} \\
T_{e}=2.5 p \lambda i_{q 1}
\end{gathered}
$$

where:

$R$ is the resistance of stator windings;

$i_{q 1}$ and $i_{d 1}$ are primary $q$ and $d$ axis currents;

$i_{q 2}$ and $i_{d 2}$ are secondary $q$ and $d$ axis currents;

$\omega_{r}$ is angular velocity of the rotor;

$v_{q 1}$ and $v_{d 1}$ are the primary $q$ and $d$ axis voltages;

$v_{q 2}$ and $v_{d 2}$ are the secondary $q$ and $d$ axis voltages;

$p$ is number of pole pairs;

$L_{d}, L_{q}$ are the $d$ and $q$ axis inductances;

$T_{e}$ is the electromagnetic torque.

The dynamic model of five phases permanent magnet synchronous motor described in equations (1)-(4) is nonlinear in nature due to the cross coupling and angular speed and the current produced in $d$ and $q$ axis respectively. The linearization process [5] of above dynamic model by considering the magnetic symmetry in the motor was given by

$$
\begin{gathered}
\frac{d}{d t} i_{q 1}=\frac{1}{L} v_{q 1}-\frac{R}{L} i_{q 1}-\frac{\lambda p \omega_{r}}{L} \\
\frac{d}{d t} i_{d 1}=\frac{1}{L} v_{d 1}-\frac{R}{L} i_{d 1} \\
\frac{d}{d t} i_{q 2}=\frac{1}{L} v_{q 2}-\frac{R}{L} i_{q 2}
\end{gathered}
$$




$$
\frac{d}{d t} i_{d 2}=\frac{1}{L} v_{d 2}-\frac{R}{L} i_{d 2}
$$

\section{Assume $L_{d}=L_{q}=L$}

The above equations represent decoupled five phases PMSM because the $d$ and $q$ axis current relations have variables in $d$ and $q$ axis only.

The mechanical model is presented by

$$
\begin{gathered}
\frac{d}{d t} \omega_{r}=\frac{1}{J} T_{e}-\frac{D}{J} \omega_{r}-\frac{T_{L}}{J} \\
\frac{d}{d t} \theta=\omega_{r}
\end{gathered}
$$

where

$J$ is the combined inertia of rotor and load. $\left(\mathrm{Kg} . \mathrm{m}^{2}\right)$

$D$ is the damping coefficient (N-m. s/rad)

$\theta$ is rotor angular position (rad)

$T_{L}$ is the load torque $(\mathrm{N}-\mathrm{m})$

The equations (5)-(10) form a continuous state space model for five phases PMSM as follows:

$$
\dot{X}=A X+B u+E w
$$

where $X$ is the state vector has the form $X=\left[\begin{array}{lllll}i_{q 1} & i_{d 1} & i_{q 2} & i_{d 2} & \omega_{r}\end{array}\right]^{T}$

$u$ is the input vector given by $u=\left[\begin{array}{llll}v_{q 1} & v_{d 1} & v_{q 2} & v_{d 2}\end{array}\right]^{T}$

$w$ is the disturbance input of the system.

The matrices $A, B$ and $E$ of the above state space are as follows:

$$
A=\left[\begin{array}{ccccc}
\frac{-R}{L} & 0 & 0 & 0 & \frac{-\lambda p}{L} \\
0 & \frac{-R}{L} & 0 & 0 & 0 \\
0 & 0 & \frac{-R}{L} & 0 & 0 \\
0 & 0 & 0 & 0 & \frac{-R}{L} \\
\frac{2.5 p \lambda}{J} & 0 & 0 & 0 & \frac{-D}{J}
\end{array}\right] B=\left[\begin{array}{cccc}
\frac{1}{L} & 0 & 0 & 0 \\
0 & \frac{1}{L} & 0 & 0 \\
0 & 0 & \frac{1}{L} & 0 \\
0 & 0 & 0 & \frac{1}{L} \\
0 & 0 & 0 & 0
\end{array}\right] E=\left[\begin{array}{c}
0 \\
0 \\
0 \\
0 \\
-\frac{1}{J}
\end{array}\right]
$$

By using field oriented control method $i_{d 1}, i_{q 2}, i_{d 2}$ are kept zero [6] and the stator current vector is kept along the primary $q$ axis and the electromagnetic torque is directly proportional to the primary $q$ axis current and is determined by closed loop control method.

The new state space model can be

$$
\begin{gathered}
\dot{\mathrm{X}}=A X+B u+E w \\
Y=C X
\end{gathered}
$$


where $X=\left[i_{q 1}, \omega_{r}, \theta\right]^{T}, u=v_{q 1}, w=T_{L}$

$$
A=\left[\begin{array}{ccc}
\frac{-R}{L} & \frac{-\lambda p}{L} & 0 \\
\frac{2.5 p \lambda}{J} & \frac{-D}{J} & 0 \\
0 & 1 & 0
\end{array}\right] \quad B=\left[\begin{array}{c}
\frac{1}{L} \\
0 \\
0
\end{array}\right] \quad E=\left[\begin{array}{c}
0 \\
\frac{-1}{J} \\
0
\end{array}\right] \quad C=\left[\begin{array}{lll}
0 & 1 & 0
\end{array}\right]
$$

\section{Optimal Linear Quadratic Regulator}

Optimal control aims to operate a dynamic system with minimum cost. The linear quadratic problem means that the system described by the set of linear differential equations and the cost is described by a quadratic function. Linear Quadratic Regulator (LQR) is a feedback controller [7], [8] which can provide the solution to the linear quadratic problem. The equations describing the linear quadratic regulator are shown below.

The cost function for the linear quadratic regulator is defined as

$$
J=\frac{1}{2} \int_{0}^{\infty}\left(x^{T} Q x+u^{T} R u\right) d t
$$

where $Q$ is the symmetric semi-positive or positive definite matrix and $R$ is the symmetric positive definite matrix.

The feedback control law that minimizes the cost function is

$$
u=-K x
$$

where $K$ is the optimal feedback gain matrix and is given by $K=\left[\begin{array}{lll}k_{1} & k_{2} & k_{3}\end{array}\right]$ which makes the cost function minimum by satisfying the equation:

$$
K=R^{-1} B^{T} P
$$

where $P$ is the real positive definite solution, it can be obtained by solving a continuous time Riccati differential equation [9]:

$$
A^{T} P+P A-P B R^{-1} B^{T} P+Q=0
$$

In order to obtain the fast and dynamic response of the system, the weight matrices $Q$ and $R$ must be chosen properly [10]. And are given by $Q=\operatorname{diag}\left[\begin{array}{lll}100 & 1 & 1\end{array}\right]$ and $R=1$.

The simulation are carried out in this paper by using the five phase permanent magnet synchronous motor parameters as

$$
R=0.12 \Omega, L=1350 \mu \mathrm{H}, p=4, \lambda=0.05 \mathrm{wb}, J=0.002 \mathrm{Kg} . \mathrm{m}^{2}, D=0.02 \mathrm{~N}-\mathrm{m} . \mathrm{s} / \mathrm{rad}
$$

By substituting the parameters in equation (13) we get 


$$
A=\left[\begin{array}{ccc}
-88.89 & -148.15 & 0 \\
370.4 & -10 & 0 \\
0 & 1 & 0
\end{array}\right], B=\left[\begin{array}{c}
740.74 \\
0 \\
0
\end{array}\right]
$$

The corresponding optimal feedback gain matrix is $K=\left[\begin{array}{lll}9.9112 & 0.6101 & 1.0000\end{array}\right]$.

\section{Results and Discussion}

Simulations are carried out by using Simulink environment in MATLAB as the simulation tool to validate the performance of five phases PMSM using Linear Quadratic Regulator (LQR). Fig. 1 and Fig. 2 show the detailed Simulink models for PI and LQR.

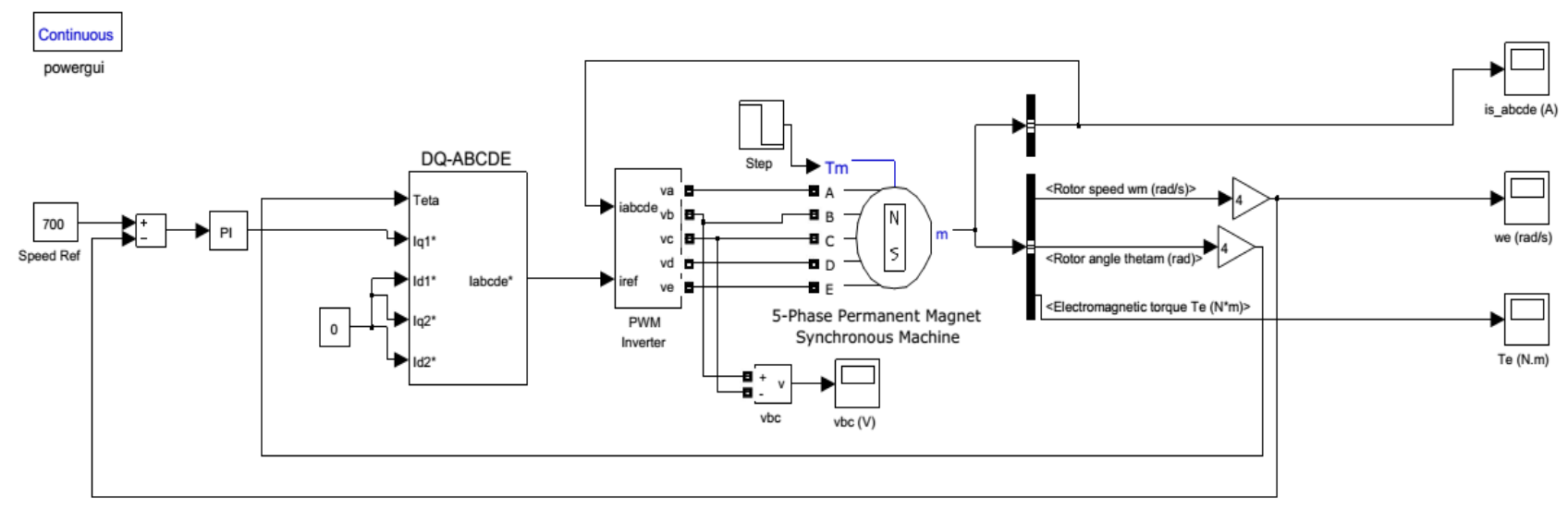

Fig. 1. Simulink model using PI controller.

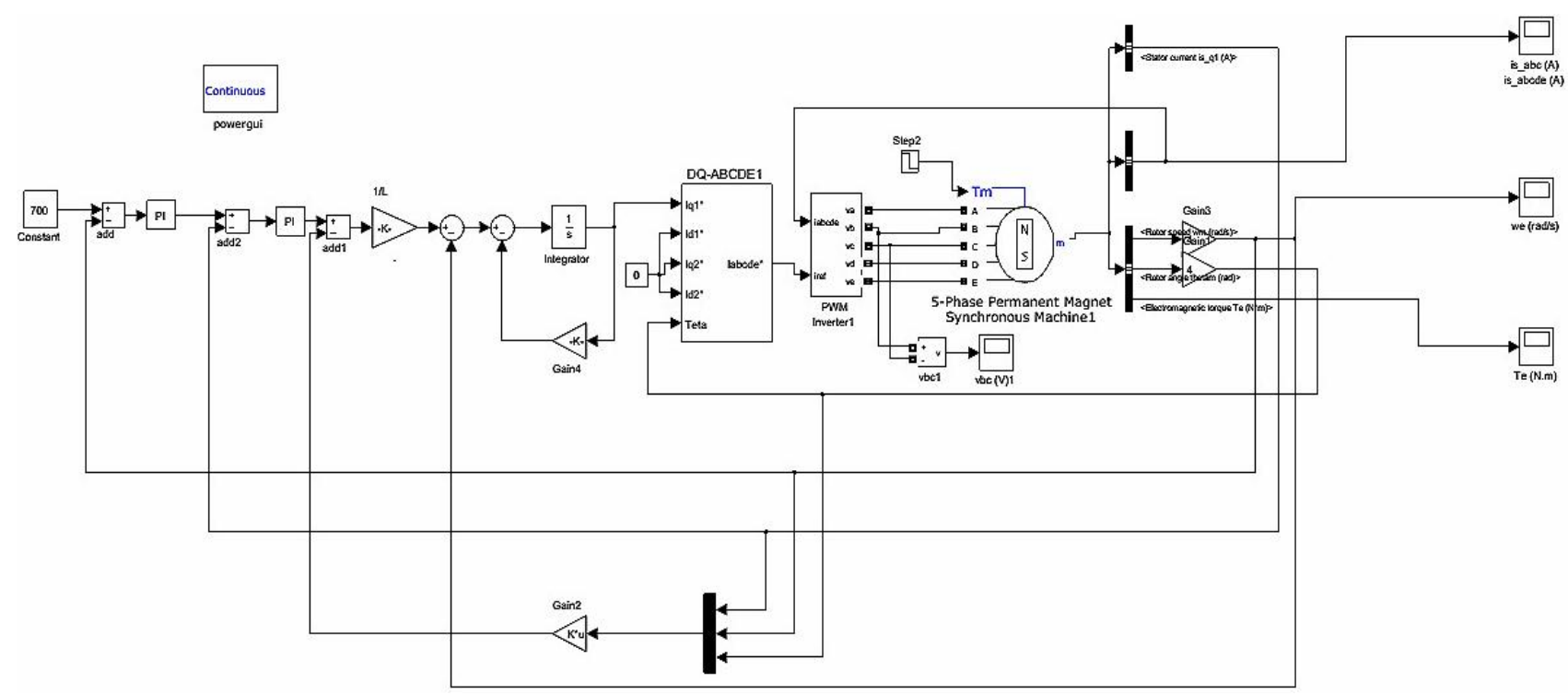

Fig. 2. Simulink model using LQR.

Fig. 3 and Fig. 4 give the speed response of five phases PMSM using traditional PI and the LQR control strategy. By observing the speed response the five phase PMSM, it has dynamic behavior for change in Load from $15 \mathrm{~N}$. $\mathrm{m}$ to $2 \mathrm{~N}$. $\mathrm{m}$ at time $t=0.1 \mathrm{sec}$ and also have less peak overshoot with LQR compared to traditional PI controller.

Fig. 5 and Fig. 6 are the Stator currents and electromagnetic torque waveforms for the five phases PMSM using traditional PI and LQR control strategies. 


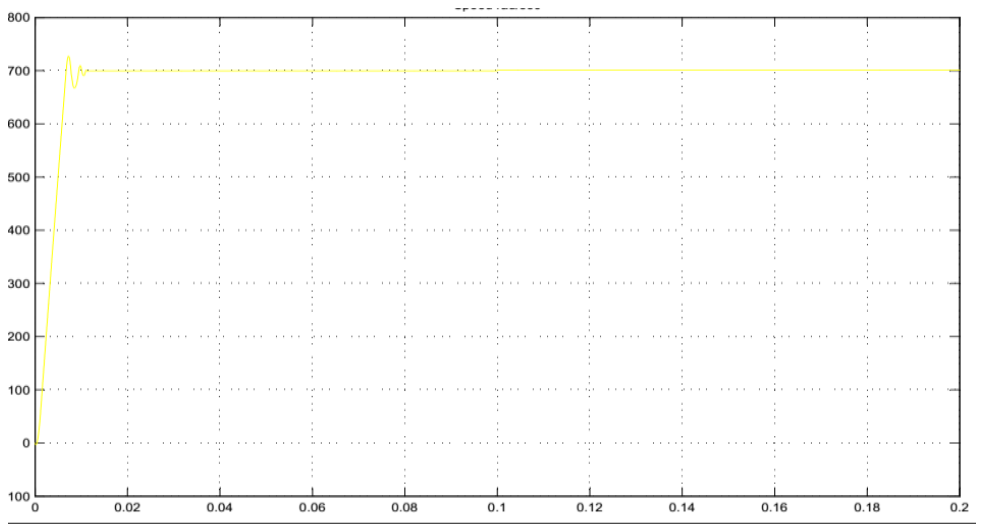

Fig. 3. Speed response with PI controller.

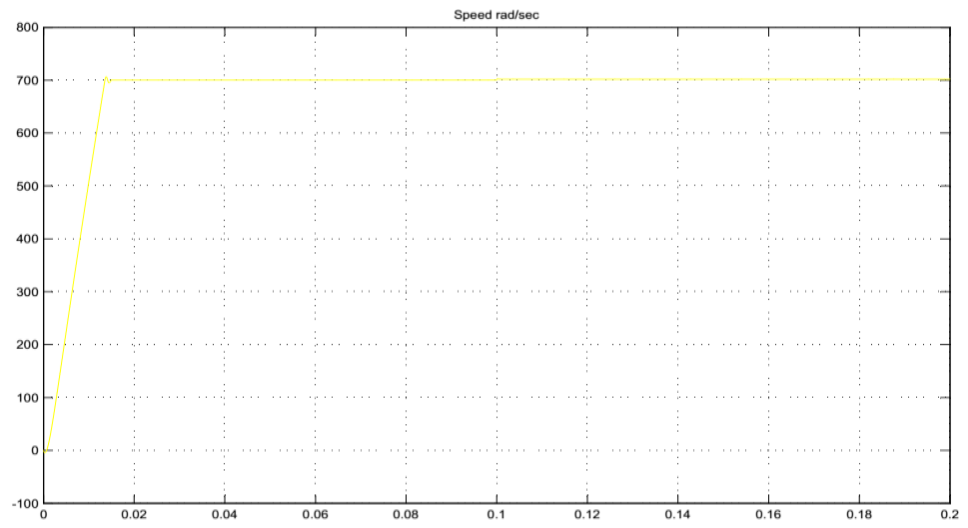

Fig. 4. Speed response with LQR.

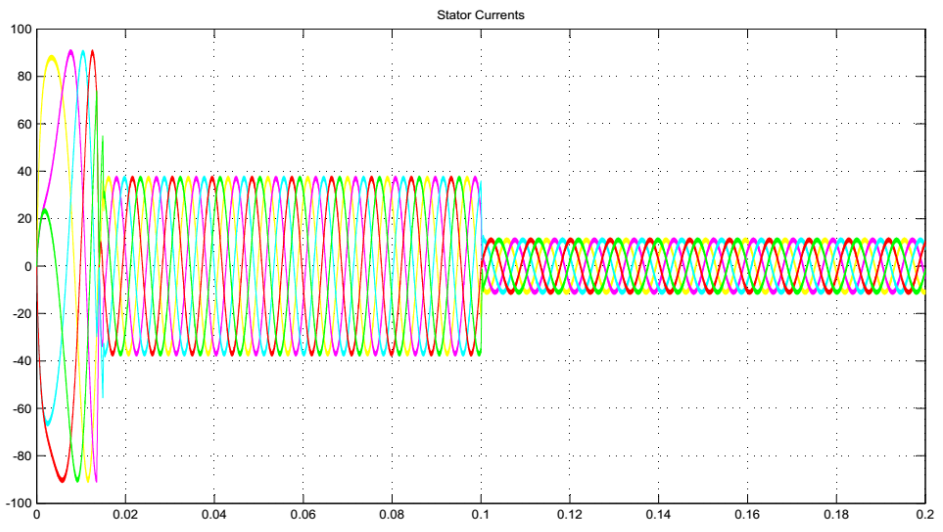

Fig. 5. Stator current waveform for both PI and LQR.

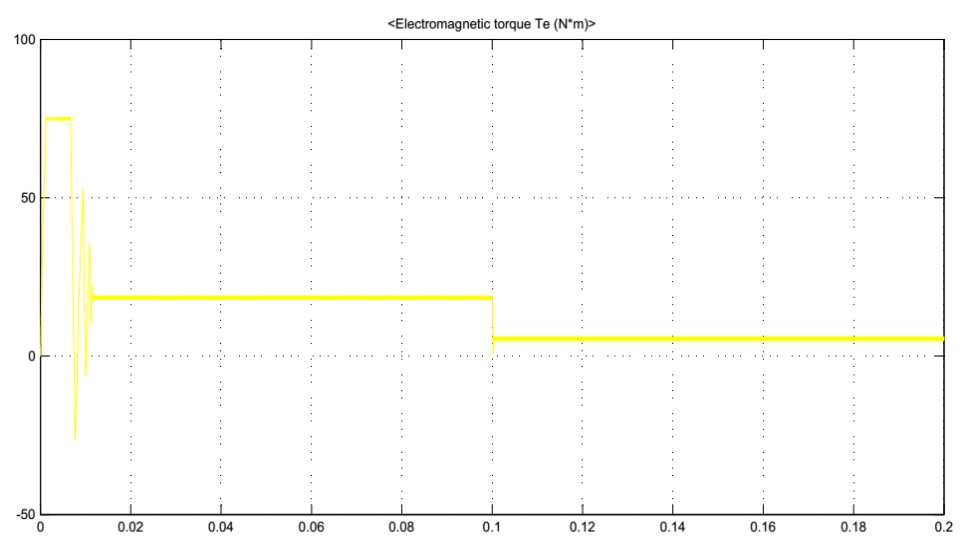

Fig. 6. Electromagnetic torque waveform for both PI and LQR. 


\section{Conclusion and Future Scope}

In this paper. the detailed mathematical model of five phases PMSM was set up by considering the nonlinear behavior and cross coupling. The linearized model was obtained by using field oriented control and assuming $i_{d 1}, i_{q 2}, i_{d 2}$ as zero. The linear quadratic regulator control strategy was investigated and the control performance is compared with the traditional PI control

In future this paper can be extended by increasing the number of phases and the control strategy can be modified as Linear Quadratic Gaussian (LQG), H-infinity and fractional order $\left(P I^{\lambda} D^{\gamma}\right)$ controller to investigate the performance of the system.

\section{References}

[1] Xu, Y. P., Zhong, Y. R., \& Yang, H. (2008). Research on vector control and direct torque control for permanent magnet synchronous motors. Power Electronics, 42(1), 60-62.

[2] Yin, M., Cong, W., Lin, J., \& Wang, L. (June 2010). Optimal speed control of PMSM for electric propulsion based on exact linearization via state feedback. Proceedings of the IEEE International Conference on ICIA (pp. 1972-1977).

[3] Molavi, R., \& Khaburi, D. (October 2008). Optimal control strategies for speed control of permanent magnet synchronous motor drives. Proceedings of World Academy of Science, Engineering and Technology: Vol. 34 (pp. 428-432).

[4] Grzesiak, L. M., \& Tarezewski, T. (2008). Permanent magnet synchronous servo-drive with state position controller. Proceedings of 13th Power Electronics and Motion Control Conference (pp. 1071-1076).

[5] Toliyat, H. A., Rahimian, M. M., \& Lipo, T. A. (1993). Analysis and modeling of five phase converters for adjustable speed drive applications. Proceedings of Fifth European Conference on Power Electronics and Applications: Vol. 5 (pp. 194-199). Brighton, UK.

[6] Pillay, P., \& Krishnan, R. (Mar./Apr. 1989). Modeling, simulation, and analysis of permanent magnet motor drives the permanent-magnet synchronous motor drive. IEEE Transactions on Industry Applications, 25, 265-273.

[7] Mademlis, C., \& Margaris, N. (December 2002). Loss minimization in vector-controlled Interior permanent-magnet synchronous motor drives. IEEE Transactions on Industrial Electronics, 49(6).

[8] Raymond, B. S., \& Lang, J. H. (July/August 1991). Real-time adaptive control of the permanent-magnet synchronous motor. IEEE Transactions on Industrial Applications, 27(4), 704-716.

[9] Banks, H. T., Lewis, B. M., \& Tran, H. T. (March 2007). Nonlinear feedback controllers and compensators: A state-dependent Riccati equation approach. Journal of Computational Optimization and Applications, 37(2), 177-218.

[10] Wang, C. X. (2003). Study of the weight matrix in LQR optimal control system. Journal of Northwest Minorities University (Natural Science), 24(2), 29-31.

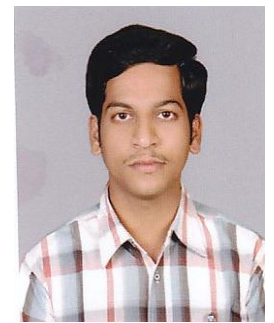

N. Venkata Ramana is currently working as an assistant professor in the EEE Department at Shri Vishnu Engineering College for Women (Autonomous), Bhimavaram. He completed his M.Tech degree in SRI VASAVI Engineering College with the specialization power electronics. He completed his under graduation in the stream of electrical and electronics engineering in SWARNADHRA College of Engineering \& Technology, Narsapur, and Andhra Pradesh. He is presently a life member of International Association of Engineers (IAENG), International Association of Computer Science and Information Technology (IACSIT) and Universal Association of Computer and Electronics Engineers (UACEE). His areas 
of interest are power electronic drive systems, simulation of power electronic converters.

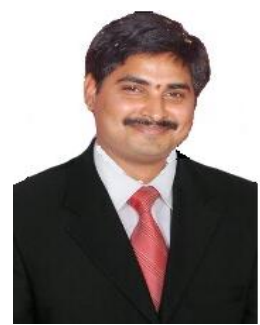

V. L. N. Sastry completed his B.Tech degree with specialization of E.E.E in SASI Institute of Technology and Engineering in 2008. He completed his M.Tech degree in the stream of instrumentation and control systems in JNTU Kakinada, 2010. He has been working as an assistant professor in the Department of E.E.E in SASI Institute of Technology and Engineering at Tadepalligudem for last 4 years. He is presently a life member of Solar Energy Society of India (SESI), member of International Association of Engineers (IAENG) and International Association of Computer Science and Information Technology (IACSIT). He has various publications in reputed international journals on image fusion, power electronics. His areas of research include neural networks and fuzzy control, electrical machines and drive systems, DSP and FPGA based control techniques for power electronic converters. 